\title{
European Network of Scientists for Social and Environmental Responsibility (ENSSER)
}

\author{
Hartmut Meyer · Almut B. Heinrich
}

Received: 30 August 2010/ Accepted: 31 August 2010/Published online: 25 September 2010

(C) Springer-Verlag 2010

\section{Background}

For many years, we have numerous controversies within the scientific community as well as in the public sphere regarding techno-scientific issues with potentially long-lasting consequences for the future development of our societies, humankind and our planet. Some of the diverse and most prominent examples are climate change, loss of biodiversity, development of agro-food systems (GMOs, biotechnology, biosafety, food sovereignty), emerging technologies (e. g. nanotechnologies), degradation of ecosystem services, and agricultural policy.

Furthermore, uncertainties in scientific results, inadequate scientific knowledge, narrow risk assessments, premature commercialization, lack of alternatives in research to counterbalance dominant technological approaches, the loss of diversity in science, the imperative of competitiveness and forced economic valorisation of research, and thus the relationship between science, technology and democracy as a whole need reflection and reaction more than ever before.

More independent research is needed, integrating knowledge from different scientific disciplines, new research questions and methodological approaches, including a broadening of the discussion on the required science and level of evidence, creating new and permanent links to other nonscientific knowledge systems, and reducing the influence of

\section{H. Meyer}

ENSSER Co-ordinator,

In den Steinäckern 13, 38116 Braunschweig, Germany

e-mail: hmeyer@ensser.org

\section{A. B. Heinrich $(\square)$}

Managing-Editor on behalf of Springer-Verlag,

Kirschgartenstr. 91, 69126 Heidelberg, Germany

e-mail: ABH.scientificjournals@googlemail.com industry on those knowledge systems that should be used to assess and control its activities.

Many critical scientists feel that the moment has come and must be seized to focus the debates constructively towards the development of new concepts, in particular for the assessment of techno-scientific developments. Establishing a platform that allows scientists in Europe to discuss their views amongst them and to coordinate and publicize their opinions beyond the respective national science circles and to European societies at large could be one answer.

In the summer of 2008, a group of scientists recommended that a European network of scientists should be formed to give a stronger voice to those scientists who develop their hypotheses, concepts and methodologies independently from the commercial application of the technology.

\section{Mission}

The European Network of Scientists for Social and Environmental Responsibility (ENSSER) forms a joint pool of critical and independent expertise to work in two fields:

1. To assess the ecological, health, and socioeconomic effects of the application of existing and future science and technologies.

2. To assess alternative options to mainstream science and technologies with the aim to strengthen citizens' interests over vested and corporate interests.

The purpose of the European Network of Scientists for Social and Environmental Responsibility e. V. (ENSSER) is the advancement of science and research for the protection of the environment, biological diversity and human health against negative impacts of new technologies and their products. ENSSER advocates the use of science and technology in the public interest. This means benign and 
peaceful uses of natural processes, scientific discoveries and technological developments, while expanding diverse approaches to them. ENSSER considers critical thinking and options analysis to be crucial for solving current social and environmental problems and for meeting future challenges through sustainable, humane development. ENSSER promotes the critical European and international discourse on new technologies, their impacts and their regulation.

As a fundamental obstacle, scientific and technological activities - and their gaps - are increasingly driven by private interests. Consequently, other social and environmental needs are largely neglected in mainstream research activities. The relationship between science, society and environment has to be restructured. In this context, ENSSER will contribute to the questioning and redefining of current models of progress and economic growth. ENSSER will promote more democratic and participatory agendasetting processes. This requires the creation of spaces for scientific work independent from the influence of the developers and owners of current technologies. For ENSSER, this also includes the identification, use, and quality assessment of scientific, lay, local, traditional and other knowledge sources.

\section{Aims}

- To promote critical thinking fora for scientists.

- To elaborate ethical and legal criteria with respect to the development and application of science and technology, by integrating transparency, accountability, social equity, public information, public participation and access to justice.

- To promote the use of the precautionary principle in the context of lack of knowledge, scientific ignorance and uncertainty where there may be serious or irreversible threats to health, social integrity and the environment.

- To improve the quality of basic and regulatory science used in the risk analysis of existing and emerging technologies and their products such as genetically modified organisms, chemicals, food technologies, geo-engineering, nanomaterials, and synthetic biology, including the risk of their military use.

- To provide information to the public and to cooperate with citizens' movements which provide public knowledge for the above regulatory or political processes.

- To promote new forms of discourse, interaction and communication between science and society by using innovative means such as the arts, social sciences and participatory approaches to research.

- To support early-warning scientists and promote their protection from discrimination.

\section{Support and Defense}

A key aim of ENSSER is to support and defend critical and independent science and research. ENSSER is aware of the increasing corporate influence and control on the agenda setting and conduct of science and research. At the same time, there is an increasing demand by the public and regulators to demonstrate safety and sustainability of production processes and industrial products through scientific research. In this context, the research and results of scientists who are not embedded in corporate interest networks is of high interest and value. Not surprisingly, results and their interpretations of independent scientists attract specific attention by all stakeholders in case they do not confirm the results and interpretations of corporate interest networks. Apart from legitimate criticism on technical issues, ENSSER has observed an increasing tendency to attac and discredit internally and publically the scientists who produce dissenting results and interpretations. ENSSER is dedicated to provide a public forum to document and analyse these controversies and attacs.

\section{Board of Directors}

The ENSSER board currently has seven members:

\section{Chairperson}

Dr. Angelika Hilbeck (Switzerland)

Institute of Integrative Biology

Department of Environmental Sciences

Swiss Federal Institute of Technology Zurich

\section{Deputy Chairperson}

Dr. Christian Velot (France)

Institut de Génétique et Microbiologie

Université Paris-Sud, Centre Scientifique d'Orsay

\section{Secretary}

Dr. Rosa Binimelis (Spain)

Barcelona

\section{Treasurer}

Dr. David Quist (Norway)

GenØk - Centre for Biosafety

\section{Non-executive Members}

Claudia Neubauer (France)

Fondation Sciences Citoyennes

Paris

Dr. Ricarda Steinbrecher (United Kingdom)

EcoNexus

Oxford 
Dr. Andras Szekacs (Hungary)

Plant Protection Institute

Department for Ecotoxicology and Environmental Analysis Hungarian Academy of Sciences, Budapest

\section{Activities}

The ENSSER Strategy Meeting in September 2009 determined three focal areas in which ENSSER should be active:

1. Democratising Science and Decision Making

2. Developing Responsible Approaches to Risk Assessment and Biosafety

3. Increasing Public Information

In each focal area, several initatives were developed. Currently, ENSSER runs three initiatives:

1.1 Support and Defense: Protecting Whistleblowing and Dissenting Scientists

2.1 Reforming the GMO Approval System

3.1 Scientific Conference in Nagoya/Japan in October 2010

7 Advancing the Understanding of Biosafety: Latest scientific findings, policy responses and public participation, October 7-9 Nagoya, Japan

The four organisations

- European Network of Scientists for Social and Environmental Responsibility (ENSSER),

- Nagoya University, Graduate School of Environmental Studies,

- Third World Network (TWN), and

- Vereinigung Deutscher Wissenschaftler (VDW, Federation of German Scientists)

are announcing as organizers the international symposium "Advancing the Understanding of Biosafety“. The symposium will be convened from October 7-9 in Nagoya/Japan, just before the 5th meeting of the members of the Cartagena Protocol on Biosafety (MOP-5) will take place.

The Symposium is endorsed by the following organisations:

- European Environment Agency (EEA), Denmark

- International Network of Engineers and Scientists for Global Responsibility (INES)

- Unión de Científicos Comprometidos con la Sociedad (UCCS), Mexico

7.1 Dates and venues

1) Scientific Findings

7 October $2010(14: 00-18: 15)$

8 October $2010(09: 00-18: 00)$

9 October 2010 (09:00-12:45)
Language: English

Lecture Hall at Graduate School of Environmental Studies Building, Nagoya University, Higashiyama-Campus.

2) Policy Responses and Public Participation

9 October 2010 (15:00-18:00)

Language: English and simultaneous translation into Japanese.

Large Lecture Hall at IB Building, Nagoya University, Higashiyama-Campus.

\subsection{Documentation}

Abstracts of the lectures will be available in September. The lectures will be posted after the Symposium.

\subsection{Programme}

Oct 7 (14:00) - Opening Session

- Welcome and introduction tbd (Nagoya University, Graduate School of Environmental Sciences)

Yoke-Ling Chee (Third World Network, Director)

Dr. Angelika Hilbeck (ENSSER, Chairperson)

Oct 7 (14:45) - Key Note Lectures

- Outlook on the Fifth Meeting of the Cartagena Protocol on Biosafety (MOP5)

Christine von Weizsäcker (VDW), Germany

- Maize Native Landraces, Transgenic Maize, Food Security and Cultural Conflicts in Mexico

Prof. Antonio Turrent Fernández (INIFAP and UCCS), Mexico

- India's Bt Brinjal: From the Supreme Court to Science in Public Debate - How Civil Society Prevailed against Monsanto and the Regulator

Aruna Rodrigues (Petitioner at the Supreme Court), India

- Assessing Systemic Risks: A Holistic Concept

Dr. Broder Breckling (University of Vechta), Germany

Oct 8 (09:00) - Risk Assessment: An Appraisal of Current Approaches

- Sound Science: Assessment of Applications sent to the European Food Safety Agency

Dr. Andreas Heissenberger (Umweltbundesamt - Environment Agency Austria), Austria

- Bt Crops - Controversies Around the Science Necessary for Risk Assessment

Dr. Angelika Hilbeck (ETH Zürich), Switzerland

- GM Maize and Glyphosate-Based Herbicides: Health Studies

Prof. Gilles-Eric Séralini (University of Caen), France 
- Transgenic Fish: How to Assess Contained Use Applications

Prof. Antonietta Guitierrez (University of Lima), Peru

Oct 8 (14:00) - Ecological Risk Research: From Organisms to Landscapes

- GE Viruses: Environmental Challenges

Prof. Terje Traavik (GenØk - Center for Biosafety), Norway

- Spread of Herbicide: Tolerant Canola in Japan

Prof. Masaharu Kawata (Yokkaichi University), Japan

- Transgene Flow in Small-Scale Systems: Ghana as Model

Dr. Denis Worlanyo Aheto (University of Cape Coast), Ghana

- GM Gene Flow in South African Commercial Maize Cultivation

Prof. Chris Viljoen (Free State University), South Africa

Oct 9 (09:00) - Reality Checks

- Patenting Genes and Plants: Intellectual Property Rights Transform Research and Agricultural Innovation

M. Phil. Lim Li Ching (Third World Network), Malaysia

- Yields of GM Crops: Fit for Feeding the World?

Dr. David Quist (GenØk - Center for Biosafety), Norway, in cooperation with Dr. Doug Gurian-Sherman (Union of Concerned Scientists), USA

- Bt-Resistant Target Pests: Quick Occurrence in South Africa

Prof. Johnnie van den Berg (North-West University), South Africa

- Environmental and Agronomic Issues of GE Soy in South America

Prof. Walter A. Pengue (University of General Sarmiento, Buenos Aires), Argentina
- International Assessment of Agricultural Knowledge, Science and Technology for Development - Which technology? Whose technology?

Prof. Jack Heinemann (University of Canterbury) New Zealand

Oct 9 (15:00) - Pre-COP10-MOP5 Citizen Forum on Social Sustainability and Biological Safety

Policy Reactions and Public Participation

- Overview on MOP5 and COP10 from the Perspective of Sustainability Studies

Prof. Yoshitsugu Hayashi, Nagoya University, Japan

- Important Issues for Japan at MOP5 and COP10 Christine von Weizsäcker, VDW, Germany

- Summary of the Scientific Findings of the Biosafety Conference

Hartmut Meyer, ENSSER coordinator

- Panel Discussion

Coordinator: NN (Asahi Shinbun Newspaper)

Panelist: Kiichiro Hayashi (NU)

NN (Nippon Keidanren)

Antonio Turrent Fernández (INIFAP)

Yoshitsugu Hayashi

Christine von Weizsäcker

17:45 Summary of the Day and Closure

(simultaneous translation into Japanese provided)

\section{Contact}

Hartmut Meyer

In den Steinäckern 13, 38116 Braunschweig, Germany

Phone +49-531-5168746

Fax +49-531-5168747

Mobile +49-162-1054755

e-mail hmeyer@ensser.org

Skype hartmut_meyer 